\title{
Diagnostic and prognostic value of serum miR-145 and vascular endothelial growth factor in non-small cell lung cancer
}

\author{
SARAYUT LUCIEN GEATER ${ }^{1}$, PICHITPON CHANIAD ${ }^{2}$, KESON TRAKUNRAM $^{2}$, \\ WARANGKANA KEERATICHANANONT ${ }^{1}$, SUHAIMEE BUYA $^{3}$, \\ PARAMEE THONGSUKSAI ${ }^{4}$ and PRITSANA RAUNGRUT ${ }^{2}$ \\ Departments of ${ }^{1}$ Internal Medicine and ${ }^{2}$ Biomedical Sciences and Biomedical Engineering, \\ ${ }^{3}$ Medical Data Center for Research and Innovation, ${ }^{4}$ Department of Pathology, Songklanagarind Hospital, \\ Faculty of Medicine, Prince of Songkla University, Songkhla 90110, Thailand
}

Received August 1, 2021; Accepted October 12, 2021

DOI: $10.3892 / \mathrm{ol} .2021 .13130$

\begin{abstract}
Previous studies have reported the diagnostic and prognostic value of serum microRNA (miR)-145 and vascular endothelial growth factor (VEGF) levels in various types of cancer; however, their clinical use in non-small cell lung cancer (NSCLC) remains unclear. The present study included 215 patients, 106 with NSCLC and 109 with other lung diseases (OLDs). miR-145 expression levels were determined using reverse transcription-quantitative PCR (RT-qPCR) and VEGF levels were measured using an ELISA. The diagnostic performance was assessed using a receiver operating characteristic curve and area under the curve (AUC) analysis. A Kaplan-Meier survival curve and Cox regression analysis were employed to evaluate the prognostic significance of the markers. The biological function of miR-145 was examined in A549 and H1792 cell lines. The effects of miR-145 on cell proliferation of NSCLC cells were evaluated by flow cytometry, and the expression levels of miR-145 and cell cycle-related genes were determined by RT-qPCR. The results revealed that miR-145 and VEGF exhibited fair diagnostic performance [AUC, 0.61 (95\% CI, 0.55-0.68) and AUC, 0.64 (95\% CI, 0.57-0.71), respectively]. Combining age and smoking status with miR-145 and VEGF provided the best model for differentiating patients with NSCLC from those with OLDs (AUC, 0.76; 95\% CI, 0.69-0.83). Furthermore, low serum miR-145
\end{abstract}

Correspondence to: Dr Pritsana Raungrut, Department of Biomedical Sciences and Biomedical Engineering, Songklanagarind Hospital, Faculty of Medicine, Prince of Songkla University, 15 Karnjanavanich Road, Hat Yai, Songkhla 90110, Thailand E-mail: rpritsana@gmail.com

Abbreviations: NSCLC, non-small cell lung cancer; miRNA, microRNA; VEGF, vascular endothelial growth factor; OLDs, other lung diseases; AUC, area under the curve; ROC, receiver operating characteristic; OS, overall survival

Key words: serum, miR-145, VEGF, diagnostic, prognostic, NSCLC levels were associated with poor overall survival [hazard ratio (HR), 0.48; 95\% CI, 0.27-0.85], whereas high VEGF levels were not associated with poor overall survival (HR, 1.47; 95\% CI, 0.81-2.68). In addition, the results of the in vitro experiments indicated that miR-145 decreased cell proliferation via the induction of cell cycle arrest. In conclusion, the findings of the present study suggested that combining miR-145 and VEGF levels with clinical risk factors may be a potential diagnostic scheme for NSCLC. In addition, serum miR-145 may be used as a prognostic marker. These results indicated that miR-145 may function as a tumor suppressor in NSCLC.

\section{Introduction}

Lung cancer is a prevalent type of cancer worldwide, accounting for the highest number of new cases (11.4\% of all cases) and deaths (18.0\% of all deaths) in men in 2020 (1). Despite recent advances in treatment, and although numerous molecular signatures for diagnostic and prognostic purposes have been proposed, the incidence and mortality of lung cancer remain high. Increasing evidence has suggested that circulating microRNAs (miRNAs/miRs) and proteins in the blood may be dysregulated, and associated with cancer development and progression $(2,3)$.

miRNAs, which are small single-stranded non-coding RNA molecules, serve important roles in various biological processes, such as cell proliferation, apoptosis, migration and invasion (4). miRNAs suppress gene expression at the post-transcriptional level by binding to the 3'-untranslated regions of mRNA (4). Among the miRNAs, miR-145 has been suggested to have a role in various types of cancer $(5,6)$, including non-small cell lung cancer (NSCLC) $(7,8)$. miR-145 exerts its functions by targeting specific genes, one of which is vascular endothelial growth factor (VEGF), a key regulator of angiogenesis (9). Zou et al (10) reported that miR-145 served an inhibitory role, both in vitro and in vivo, in the angiogenesis of breast cancer cells via VEGF-A regulation. Based on bioinformatics analysis in our previous study, VEGF was identified to be a downstream target gene of miR-145 (11). Therefore, the evaluation of both miR-145 and VEGF levels may provide further insight into their clinical use in NSCLC. 
Previous studies have shown that serum miR-145 and VEGF levels may be associated with diagnosis and prognosis in glioblastoma $(12)$, ovarian cancer $(13,14)$ and $\operatorname{NSCLC}(15,16)$. Although there are an increasing number of studies that have supported the possibility of using serum miR-145 and VEGF as biomarkers for various purposes in lung cancer, the reports have been unclear regarding the prognostic role of these two markers (12,15-18). Furthermore, most of the studies have been conducted using healthy individuals as the control group, which could have led to an overestimation of the diagnostic accuracy (19).

The present study aimed to investigate the diagnostic performance of serum miR-145 and VEGF levels in patients with NSCLC and included patients with other lung diseases (OLDs) as the control group. The prognostic role of the two markers and the biological function of miR-145 in NSCLC cells were also evaluated.

\section{Materials and methods}

Study participants and blood samples. Clinical information on the study participants, as well as remaining samples, were obtained from our two previous studies following ethics approval from the Human Research Ethics Committee of the Faculty of Medicine, Prince of Songkla University (Songkhla, Thailand; approval nos. 59-011-05-1 and 60-350-04-2) (11,20). The participants were enrolled at Songklanagarind Hospital (Songkhla, Thailand) between January 2016 and December 2018. From the original 230 samples (117 NSCLC and 113 OLDs) of the previous study, 215 samples (106 NSCLC and 109 OLDs) were adequately obtained for the analysis of miR-145 expression and 183 samples (92 NSCLC and 91 OLDs) for VEGF determination. Patients with suspected lung cancer were included if they presented with a chronic cough for $\geq 8$ weeks or hemoptysis more than once. In addition, information on smoking and drinking status, as well as the family history of cancer, for each participant were obtained by interviewing the patients. The demographic and clinical characteristics of the patients were retrieved from the hospital registry. Patients with a previous history of cancer or chemotherapy were excluded. During or after data collection, no personal information that could be used to identify individuals was available.

Confirmation of cancer was obtained via a pathological diagnosis. The histological type of NSCLC was diagnosed according to the 2015 World Health Organization classification of lung and pleural tumors (21). The clinical staging was based on the Tumor Node Metastasis staging system of the Cancer Staging Manual (7th Edition) of the American Joint Committee on Cancer (22). Patients with OLDs were diagnosed via routine procedures, including laboratory tests, chest $\mathrm{X}$-rays and tissue biopsies. The mortality data were obtained from the civil registry.

Peripheral blood $(5 \mathrm{ml})$ was collected at the time of diagnosis after the patients had provided their written informed consent, and samples were processed as previously described $(11,20)$. Briefly, blood samples were coagulated for $30 \mathrm{~min}$ at room temperature and centrifuged at $3,400 \mathrm{x} \mathrm{g}$ for $10 \mathrm{~min}$ at room temperature. Isolated serum was filtered through a polyvinylidene difluoride syringe filter with a pore size of 0.22-mm (cat. no. SLGS033SB; MilliporeSigma) and prepared for miRNA isolation.

Cell culture. Human NSCLC cell lines, A549 and H1792 (both lung adenocarcinoma), were purchased from the American Type Culture Collection. Cells were cultured in RPMI-1640 medium (cat. no. R6504; Sigma-Aldrich; Merck KGaA) supplemented with $10 \%$ (v/v) FBS (cat. no. 10091148; Gibco; Thermo Fisher Scientific, Inc.), and maintained at $37^{\circ} \mathrm{C}$ in a $5 \% \mathrm{CO}_{2}$ atmosphere.

miRNA transfection. miR-145 mimic (50 nM, 5'-GUC CAGUUUUCCCAGGAAUCCCU-3') and mimic negative control (NC) (50 nM, 5'-UCACA ACCUCCUAGAAAGA GUAGA-3') were purchased from GE Healthcare Dharmacon, Inc. Transfection was conducted using Lipofectamine ${ }^{\circledR} 2000$ (cat. no. 11668019; Invitrogen; Thermo Fisher Scientific, Inc.) according to the manufacturer's instructions. Briefly, A549 $\left(2 \times 10^{5}\right)$ and $\mathrm{H} 1792\left(4 \times 10^{5}\right)$ cells were suspended in medium containing $10 \%$ FBS and seeded into a T25 cell culture flask (Corning, Inc.) for $24 \mathrm{~h}$ before miRNA transfection. miR-145 mimic and mimic NC were diluted in Opti-MEM (cat. no. 31985088; Gibco; Thermo Fisher Scientific, Inc.), mixed with Lipofectamine 2000, and incubated for $30 \mathrm{~min}$ at room temperature. Subsequently, cells were incubated with the transfection mixture at $37^{\circ} \mathrm{C}$ in a $5 \% \mathrm{CO}_{2}$ atmosphere. Culture medium was replaced after $10 \mathrm{~h}$, and the cells were further incubated at $37^{\circ} \mathrm{C}$ in a $5 \% \mathrm{CO}_{2}$ atmosphere for 4 days. After transfection, the cells were harvested and subjected to subsequent experiments. The efficiency of miRNA transfection was confirmed via reverse transcription-quantitative PCR (RT-qPCR). Untreated cells (cell group), cells treated with Opti-MEM and Lipofectamine 2000 (mock group) and cells transfected with mimic NC (mimic NC groups) were assigned as the control groups.

Detection of miR-145 expression using RT-qPCR. Total RNA was extracted from cells using TRIzol ${ }^{\circledR}$ reagent (cat. no. 15596018; Invitrogen; Thermo Fisher Scientific, Inc.) and from serum $(250 \mu \mathrm{l})$ using a miRNeasy serum/plasma kit (cat. no. 217184; Qiagen $\mathrm{GmbH}$ ), according to the manufacturers' protocols. miR-145 expression levels were measured using RT-qPCR, as previously described (11). Briefly, total RNA (50 ng) was reverse transcribed into cDNA using the miScript II RT kit (cat. no. 218161; Qiagen $\mathrm{GmbH}$ ) at $37^{\circ} \mathrm{C}$ for $60 \mathrm{~min}$ and $95^{\circ} \mathrm{C}$ for 5 min using a thermal cycler (Bio-Rad Laboratories, Inc.). After dilution in $200 \mu \mathrm{l}$ RNase-free water, miRNA amplification was performed using a miScript SYBR $^{\circledR}$ Green PCR kit (cat. no. 218073; Qiagen, Inc.) on a CFX96 Touch Real-time qPCR Detection system (Bio-Rad Laboratories, Inc.). The miScript primer assay used for miR-145 and U6 small nuclear RNA 2 (RNU6-2, an internal control) was purchased from Qiagen, Inc. Mature miRNA sequences were used for designing the forward primers: miR-145, 5'-GUCCAGUUUUCCCAGGAAUCCCU-3' (cat. no. MS00003528; Qiagen $\mathrm{GmbH}$ ) and RNU6-2, 5' - CGCT TCGGCAGCACATATACTA-3' (cat . no. MS00033740; Qiagen $\mathrm{GmbH}$ ). The reverse primer was specifically designed for use with and contained in the miScript SYBR Green PCR kits (cat. no. 218073; Qiagen, Inc.). 
Table I. Demographic and clinical characteristics, and miR-145 and VEGF levels among the study participants.

\begin{tabular}{|c|c|c|c|}
\hline \multirow[b]{2}{*}{ Variable } & \multicolumn{2}{|c|}{ Number of patients (\%) } & \multirow[b]{2}{*}{ P-value } \\
\hline & OLD $(n=109)$ & $\operatorname{NSCLC}(n=106)$ & \\
\hline Sex & & & 0.030 \\
\hline Male & $55(50.5)$ & $69(65.1)$ & \\
\hline Female & $54(49.5)$ & $37(34.9)$ & \\
\hline Age, years & & & $<0.001$ \\
\hline$<60$ & $57(52.3)$ & $31(29.2)$ & \\
\hline$\geq 60$ & $52(47.7)$ & $75(70.8)$ & \\
\hline Smoking status & & & $<0.001$ \\
\hline Non-smoker & $69(63.3)$ & $41(38.7)$ & \\
\hline Smoker & $40(36.7)$ & $65(61.3)$ & \\
\hline Alcohol drinking & & & 0.760 \\
\hline Non-drinker & $67(61.5)$ & $63(59.4)$ & \\
\hline Drinker & $42(38.5)$ & $43(40.6)$ & \\
\hline Family history of cancer & & & 0.649 \\
\hline No & $74(67.9)$ & $75(70.8)$ & \\
\hline Yes & $35(32.1)$ & $31(29.2)$ & \\
\hline \multicolumn{4}{|l|}{ Histology } \\
\hline $\mathrm{ADE}$ & - & $77(72.6)$ & \\
\hline SCC & - & $22(20.8)$ & \\
\hline Uncertain NSCLC & - & 7 (6.6) & \\
\hline \multicolumn{4}{|l|}{ Clinical stage } \\
\hline I & - & $9(8.5)$ & \\
\hline II & - & $5(4.7)$ & \\
\hline III & - & $12(11.3)$ & \\
\hline IV & - & $80(75.5)$ & \\
\hline miR-145 expression & & & 0.002 \\
\hline Low & $20(18.3)$ & $39(36.8)$ & \\
\hline High & $89(81.7)$ & $67(63.2)$ & \\
\hline VEGF level ${ }^{\mathrm{a}}$ & & & $<0.001$ \\
\hline Low & $66(72.5)$ & $41(44.6)$ & \\
\hline High & $25(27.5)$ & $51(55.4)$ & \\
\hline
\end{tabular}

${ }^{\text {a} F e w e r ~ p a t i e n t s ~(91 ~ O L D s ~ a n d ~} 92$ NSCLC) were used for the assessment of VEGF levels. ADC, adenocarcinoma; OLD, other lung disease; miR, microRNA; NSCLC, non-small cell lung carcinoma; SCC, squamous cell carcinoma; VEGF, vascular endothelial growth factor.

The qPCR amplification conditions were as follows: $95^{\circ} \mathrm{C}$ for $15 \mathrm{~min}$ for polymerase activation, followed by 50 cycles of denaturation at $94^{\circ} \mathrm{C}$ for $15 \mathrm{sec}$, amplification at $55^{\circ} \mathrm{C}$ for $30 \mathrm{sec}$ and extension at $70^{\circ} \mathrm{C}$ for $30 \mathrm{sec}$. The difference between the cycle quantification $(\mathrm{Cq})$ value of miR-145 and RNU6-2 $(\Delta \mathrm{Cq})$ was calculated and the relative expression levels were quantified using the $2^{-\Delta \Delta \mathrm{Cq}}$ method (23).

Detection of $m R N A$ expression using RT-qPCR. Total RNA was extracted from the cells using TRIzol reagent, according to the manufacturer's protocol. To synthesize cDNA, $50 \mathrm{ng}$ total RNA was reverse transcribed using iScript ${ }^{\mathrm{TM}}$ Reverse Transcription SuperMix (cat. no. 1708840; Bio-Rad Laboratories, Inc.) at $46^{\circ} \mathrm{C}$ for $20 \mathrm{~min}$ and $95^{\circ} \mathrm{C}$ for $1 \mathrm{~min}$ using a thermal cycler. qPCR was subsequently performed using a Luna ${ }^{\circledR}$ Universal
qPCR Master Mix (cat. no. M3003L; New England BioLabs, Inc.). The following thermocycling conditions were used for the amplification of CDK4, cyclin A, CDK1 and GAPDH: $95^{\circ} \mathrm{C}$ for $5 \mathrm{~min}$ for polymerase activation, followed by 40 cycles of denaturation at $95^{\circ} \mathrm{C}$ for $10 \mathrm{sec}$, amplification at $60^{\circ} \mathrm{C}$ for $30 \mathrm{sec}$ and extension at $72^{\circ} \mathrm{C}$ for $30 \mathrm{sec}$. A CFX96 Touch Real-time qPCR Detection system was used for the analysis and the relative expression levels of the genes were calculated using the $2^{-\triangle \Delta \mathrm{Cq}}$ method (24), using GAPDH as the endogenous control. The following primer sequences were used for qPCR: CDK4, forward 5'-GGAGGCCTTTGAACATCCCA-3' and reverse 5'-ACTGGCGCATCAGATCCTTA-3'; cyclin A, forward 5'-TAGACACCGGCAACTCAAG-3' and reverse 5'-TCTTCAGACTGGGAGAGGAGA-3'; CDK1, forward 5'-TGGAGAAGGTACCTATGGAGTTG-3' and reverse 
Table II. Logistic regression analysis of predictors of the diagnosis of non-small cell lung carcinoma.

\begin{tabular}{|c|c|c|c|}
\hline Variable & Crude OR (95\% CI) & Adjusted OR (95\% CI) & P-value \\
\hline \multicolumn{4}{|l|}{ Sex } \\
\hline Male vs. female & $0.57(0.32-1.03)$ & & \\
\hline \multicolumn{4}{|l|}{ Age } \\
\hline$\geq 60$ vs. $<60$ years & $2.43(1.33-4.43)$ & $2.16(1.11-4.21)$ & 0.023 \\
\hline \multicolumn{4}{|l|}{ Smoking status } \\
\hline Smoker vs. non-smoker & $2.38(1.31-4.30)$ & $2.92(1.48-5.76)$ & 0.002 \\
\hline \multicolumn{4}{|l|}{ Alcohol drinking } \\
\hline Drinker vs. non-drinker & $1.13(0.62-2.04)$ & & \\
\hline \multicolumn{4}{|l|}{ Family history of cancer } \\
\hline Yes vs. no & $0.80(0.43-1.50)$ & & \\
\hline \multicolumn{4}{|l|}{ miR-145 expression } \\
\hline High vs. low & $0.31(0.15-0.61)$ & $0.26(0.12-0.57)$ & $<0.001$ \\
\hline \multicolumn{4}{|l|}{ VEGF level } \\
\hline High vs. low & $3.28(1.77-6.09)$ & $3.19(1.64-6.20)$ & $<0.001$ \\
\hline
\end{tabular}

miR, microRNA; OR, odds ratio; VEGF, vascular endothelial growth factor.

5'-AGGAACCCCTTCCTCTTCAC-3'; and GAPDH, forward, 5'-GACTTCAACAGCGACACCCACTCC-3' and reverse 5'-AGGTCCACCACCCTGTTGCTGTAG-3'.

ELISA. Serum VEGF levels were measured using a sandwich human ELISA kit (cat. no. 900-K10; PeproTech, Inc.) according to the manufacturer's instructions. Briefly, an ELISA plate was coated with $100 \mu$ l capture antibody and incubated overnight at room temperature. After blocking with $1 \%$ BSA (cat. no. A9418; Sigma-Aldrich; Merck KGaA) for $1 \mathrm{~h}$ at room temperature, $100 \mu \mathrm{l}$ serum sample was added to each well, followed by $100 \mu \mathrm{l}$ HRP-conjugated detection antibody, after which the reaction was incubated for $1 \mathrm{~h}$ at room temperature. After washing, colorimetric detection was performed using an avidin-HRP conjugate $(1: 2,000)$ using ABTS liquid substrate solution (cat. no. 002024; Thermo Fisher Scientific, Inc.) for $10 \mathrm{~min}$. Color development was measured at a wavelength of $405 \mathrm{~nm}$, with a reference wavelength of $650 \mathrm{~nm}$, using a microplate reader (Molecular Devices, LLC). VEGF levels were quantified using the constructed standard curve.

Cell viability assay. Cell suspension aliquots were mixed with an equal amount of $0.4 \%$ (w/v) trypan blue solution (cat. no. 15250061; Gibco; Thermo Fisher Scientific, Inc.) and the viable cells were counted under light microscopy using a hemocytometer. The number of cells in the cell group was considered as $100 \%$, whereas the number of cells in the other groups was expressed as a percentage of that compared with the cell group.

In addition, a cell suspension was prepared at a concentration of $1 \times 10^{6}$ cells $/ \mathrm{ml}$ in culture medium and a $50-\mu 1$ cell suspension was mixed with $450 \mu 1$ Muse ${ }^{\circledR}$ Count \& Viability reagent (cat. no. 637365; MilliporeSigma). The mixed cells were incubated at room temperature in the dark for $5 \mathrm{~min}$, then the live and dead cells were counted using a Muse cell analyzer (MilliporeSigma). The number of total cells in the cell group was considered as $100 \%$, whereas the number of total cells in the other groups was expressed as a percentage of that compared with the cell group. The percentage of live and dead cells in a population was determined.

Cell cycle analysis. After transfection, cells were trypsinized and centrifuged at $300 \mathrm{x}$ g for $5 \mathrm{~min}$ at room temperature. Subsequently, $1 \times 10^{6}$ cells were fixed with ice-cold $70 \%$ methanol (cat. no. 67-56-1; RCI Labscan Ltd.) overnight at $-20^{\circ} \mathrm{C}$. Fixed cells were centrifuged at $300 \mathrm{x}$ g for $5 \mathrm{~min}$ and washed with $500 \mu \mathrm{l}$ cold PBS. The cells were subsequently resuspended in $1 \mathrm{ml} 1 \mathrm{X}$ binding buffer and a 100- $\mu \mathrm{l}$ cell suspension ( $1 \times 10^{5}$ cells) was mixed with $5 \mu \mathrm{l}$ PI (cat. no. 556463; BD Biosciences) and $1 \mu \mathrm{l}$ RNase A, DNase and protease-free (10 mg/ml; cat. no. EN0531; Invitrogen; Thermo Fisher Scientific, Inc.). After incubation for $15 \mathrm{~min}$ at room temperature in the dark, $400 \mu \mathrm{l} 1 \mathrm{X}$ binding buffer was added to the cells, and the cell cycle distribution was analyzed using an Amnis ${ }^{\circledR}$ ImageStream ${ }^{\circledR X}$ Mk II and IDEAS software, version 6.0 (both Luminex Corporation). The percentage of cells distributed in each phase of the cell cycle was determined.

Statistical analysis. Statistical analysis was performed using R statistical software, version 3.4.4 (RStudio, Inc.) and GraphPad Prism 5.0 software (GraphPad Software, Inc.). The experiments were performed in triplicate. Clinical characteristics of the patients were presented as numbers and percentages. The continuous data of the cell viability assay and cell cycle analysis, which were obtained from three independent experiments, were presented as the mean \pm SD. Serum miR-145 and VEGF levels were presented as the median and interquartile range (IQR). The association between clinical variables and patient status (NSCLC and OLDs) was analyzed using a $\chi^{2}$ test. The statistical differences between multiple groups were 
A

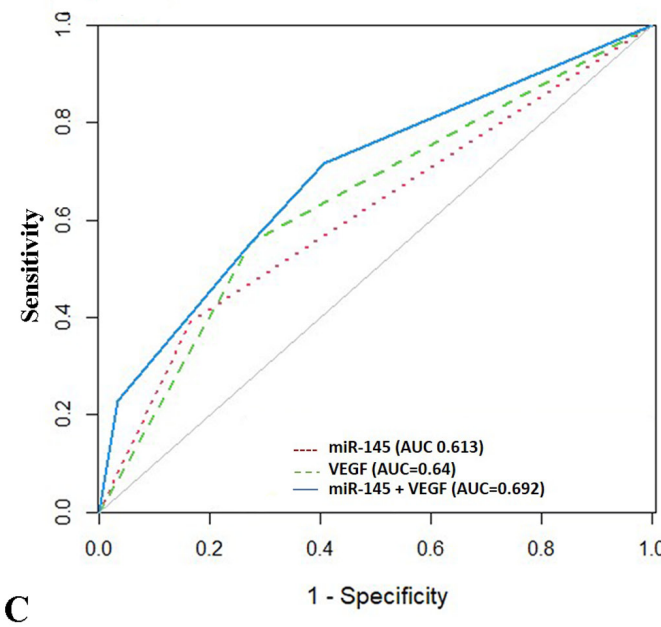

C

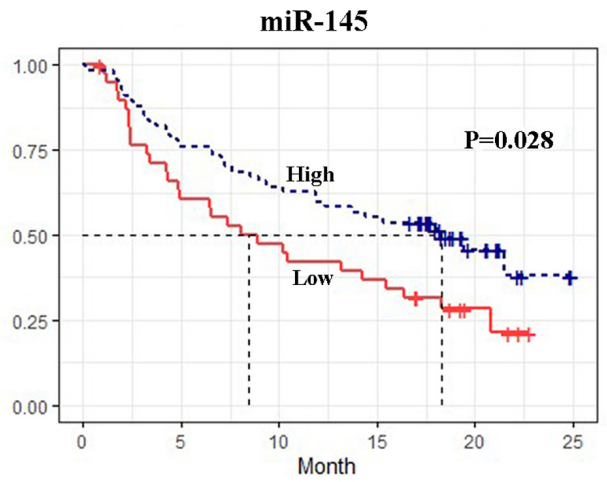

B

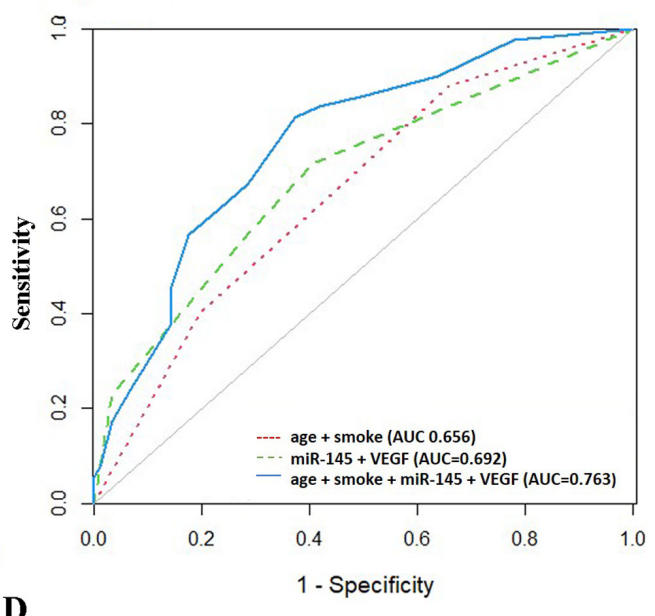

D

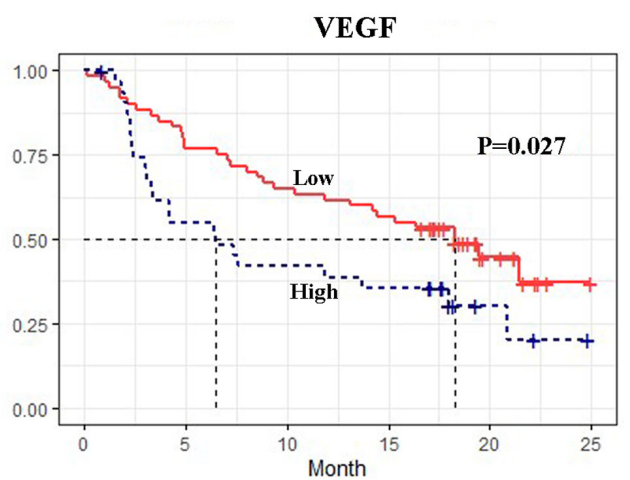

Figure 1. (A and B) Receiver operating characteristic curve analysis for the diagnosis of NSCLC. Kaplan-Meier curves of overall survival of patients with NSCLC according to (C) miR-145 expression and (D) VEGF levels. AUC, area under the curve; NSCLC, non-small cell lung cancer; miR, microRNA; VEGF, vascular endothelial growth factor.

determined using one-way ANOVA followed by Tukey's post hoc test. Logistic regression was used to evaluate the variables associated with the cancer diagnosis. The diagnostic performance was assessed using a receiver operating characteristic (ROC) curve and area under the curve (AUC) analysis, which was reported with 95\% CIs. The cut-off values for miR-145 and VEGF were obtained from the best coordinate in the ROC to provide a maximum sum of sensitivity and specificity. For the survival analysis, a Kaplan-Meier curve was constructed and the statistical differences in overall survival (OS) among the various categories of variables were determined using a log-rank test. A multivariate Cox proportional hazards model was used to identify independent prognostic variables. $\mathrm{P}<0.05$ was considered to indicate a statistically significant difference.

\section{Results}

Demographic and clinical characteristics of the patients. The present study included 215 patients, 106 with NSCLC and 109 with OLDs. The diagnoses for the patients with OLDs were tuberculosis, bronchiectasis, interstitial lung disease, pneumonia or chronic obstructive pulmonary disease. Table I lists the clinicopathological characteristics of the patients, and shows the significant differences identified in $\operatorname{sex}(\mathrm{P}=0.030)$, age $(\mathrm{P}<0.001)$ and smoking status $(\mathrm{P}<0.001)$ between the NSCLC and control groups. There were no significant differences identified between the two groups for alcohol consumption and family history of cancer.

Serum miR-145 and VEGF levels. The median serum miR-145 level was lower in the NSCLC group (17.15; IQR, 1.50-136.72) compared with that in the control group (25.46; IQR, 4.56-109.90). The median VEGF level was higher in the NSCLC group (0.04; IQR, 0.02-0.05) compared with that in the control group $(0.02 ; \mathrm{IQR}, 0.00-0.03)$. The cut-off values for miR-145 and VEGF levels were set as follows: $\leq 3.434$ for miR-145 and $\leq 0.032$ for VEGF for the lower value and $>0.434$ for miR-145 and $>0.032$ for VEGF for the upper value. A larger proportion of the NSCLC group had lower miR-145 levels compared with those in the control group (36.8 vs. $18.3 \%$; $\mathrm{P}=0.002$; Table I). By contrast, a larger proportion of the NSCLC group had higher VEGF levels compared with those in the control group (55.4 vs. $27.5 \%$; $\mathrm{P}<0.001)$.

Diagnostic performance of serum miR-145 and VEGF. The logistic regression analysis revealed that smoking status, and miR-145 and VEGF levels were significant predictors for diagnosing NSCLC (Table II). Age also exhibited a moderate trend as a predictor $(\mathrm{P}=0.023)$. Low miR-145 expression levels [adjusted odds ratio (aOR), 0.26; 95\% CI, 0.12-0.57] and high VEGF expression levels (aOR, 3.19; 95\% CI, 1.64-6.20) were associated with a NSCLC diagnosis. 
Table III. Discriminative performance of miR-145, VEGF and clinical factors for the diagnosis of non-small cell lung carcinoma.

\begin{tabular}{llcr}
\hline \multirow{2}{*}{ Variable } & \multicolumn{2}{c}{ Diagnostic performance } \\
\cline { 2 - 4 } & AUC $(95 \% \mathrm{CI})$ & Sensitivity $(95 \% \mathrm{CI})$ & Specificity (95\% CI) \\
\hline miR-145 & $0.61(0.55-0.68)$ & $0.39(0.29-0.49)$ & $0.84(0.76-0.91)$ \\
VEGF & $0.64(0.57-0.71)$ & $0.55(0.45-0.65)$ & $0.73(0.63-0.81)$ \\
miR-145 + VEGF & $0.69(0.62-0.76)$ & $0.70(0.27-0.80)$ & $0.64(0.52-0.97)$ \\
Age + Smoking & $0.76(0.69-0.83)$ & $0.80(0.55-0.89)$ & $0.66(0.54-0.87)$ \\
+ miR-145 + VEGF & & &
\end{tabular}

AUC, area under the curve; miR, microRNA; VEGF, vascular endothelial growth factor.

Table IV. Cox regression analysis for overall survival in non-small cell lung carcinoma ( $\mathrm{n}=106)$.

\begin{tabular}{|c|c|c|c|c|c|c|}
\hline \multirow[b]{2}{*}{ Variables } & \multicolumn{3}{|c|}{ Univariate analysis } & \multicolumn{3}{|c|}{ Multivariate analysis } \\
\hline & HR & $95 \% \mathrm{CI}$ & $\mathrm{P}$-value & HR & $95 \% \mathrm{CI}$ & P-value \\
\hline \multicolumn{7}{|l|}{ Sex } \\
\hline Male & Reference & & & & & \\
\hline Female & 0.67 & $0.39-1.16$ & 0.152 & & & \\
\hline \multicolumn{7}{|l|}{ Age } \\
\hline$<60$ years & Reference & & & & & \\
\hline$\geq 60$ years & 0.89 & $0.52-1.55$ & 0.696 & & & \\
\hline \multicolumn{7}{|l|}{ Smoking status } \\
\hline Non-smoker & Reference & & & & & \\
\hline Smoker & 1.56 & $0.92-2.64$ & 0.097 & & & \\
\hline \multicolumn{7}{|l|}{ Drinking status } \\
\hline Non-drinker & Reference & & & & & \\
\hline Drinker & 1.58 & $0.96-2.6$ & 0.069 & & & \\
\hline \multicolumn{7}{|c|}{ Family history of cancer } \\
\hline No & Reference & & & & & \\
\hline Yes & 0.70 & $0.39-1.26$ & 0.237 & & & \\
\hline \multicolumn{7}{|l|}{ Staging } \\
\hline I-II & Reference & & & & & \\
\hline III-IV & 3.63 & $1.31-10.06$ & 0.013 & 3.13 & $1.10-8.90$ & 0.013 \\
\hline \multicolumn{7}{|l|}{ Histologic type } \\
\hline $\mathrm{ADC}$ & Reference & & & & & \\
\hline $\mathrm{SCC}$ & 1.13 & $0.62-2.07$ & 0.694 & 1.13 & $0.62-2.07$ & 0.693 \\
\hline Uncertain NSCLC & 3.10 & $1.31-7.34$ & 0.010 & 3.09 & $1.31-7.34$ & 0.010 \\
\hline \multicolumn{7}{|l|}{ miR-145 expression } \\
\hline Low & Reference & & & & & \\
\hline High & 0.58 & $0.35-0.95$ & 0.030 & 0.48 & $0.27-0.85$ & 0.012 \\
\hline \multicolumn{7}{|l|}{ VEGF level } \\
\hline Low & Reference & & & & & \\
\hline High & 1.84 & $1.07-3.18$ & 0.029 & 1.47 & $0.81-2.68$ & 0.203 \\
\hline
\end{tabular}

ADC, adenocarcinoma; HR, hazard ratio; miR, microRNA; NSCLC, non-small cell lung carcinoma; SCC, squamous cell carcinoma; VEGF, vascular endothelial growth factor.

The diagnostic power of miR-145 and VEGF, with or without other risk factors, was evaluated using ROC curve analysis. The AUC was 0.61 (95\% CI, 0.55-0.68) for miR-145 alone and 0.64 (95\% CI, 0.57-0.71) for VEGF alone. When 
A

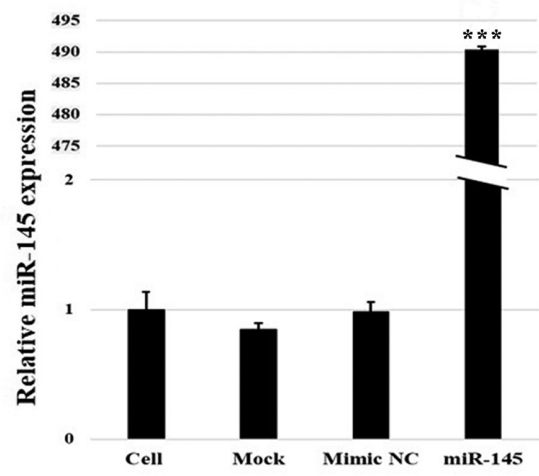

C

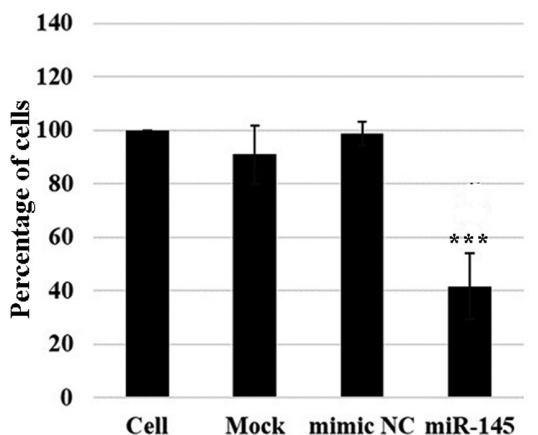

$\mathbf{E}$

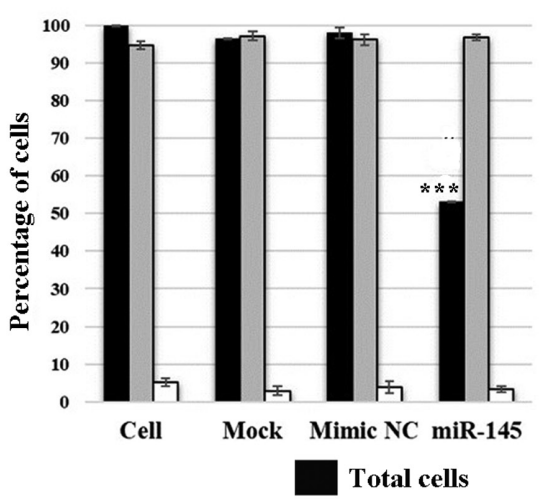

B

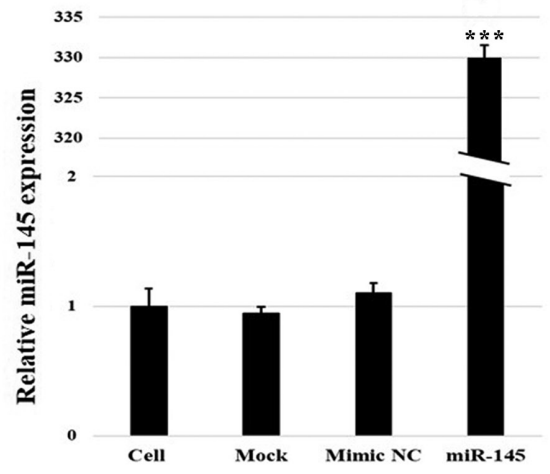

D

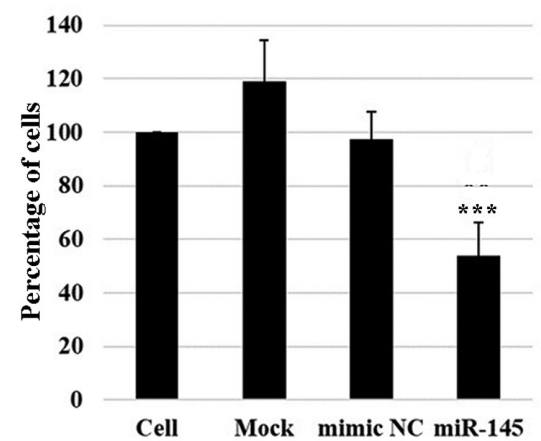

$\mathbf{F}$

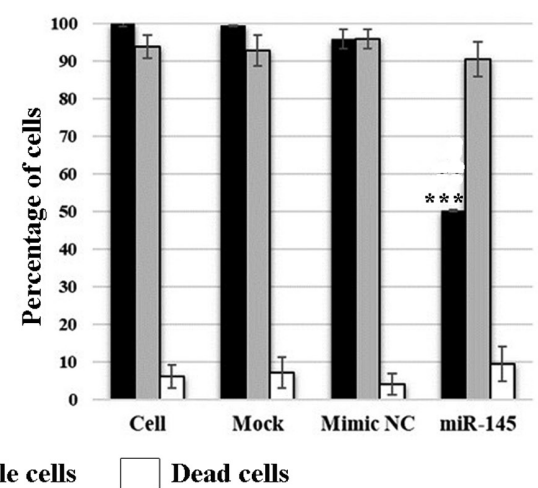

Figure 2. Reverse transcription-quantitative PCR analysis was performed to detect miR-145 expression in (A) A549 and (B) H1792 cells. Effect of upregulated miR-145 expression on viability was determined using a trypan blue assay in (C) A549 and (D) H1792 cells, and using a viability assay in (E) A549 and (F) H1792 cells. The cell group was set as $100 \%$. All experiments were performed in triplicate on cell-culture passages $10-30$. Data are presented as the mean \pm SD of three independent experiments. ${ }^{* * *} \mathrm{P} \leq 0.001$ vs. cell group. miR, microRNA; NC, negative control.

combined, miR-145 and VEGF improved the discrimination, with an AUC of 0.69 (95\% CI, 0.62-0.76) (Fig. 1A). The combination of age, smoking status, miR-145 and VEGF expression proved to be the best model for differentiating patients with NSCLC from those with OLDs (AUC, 0.76; 95\% CI, 0.69-0.83), with an optimal sensitivity and specificity of 80.4 and $65.9 \%$, respectively (Table III; Fig. 1B).

Association between serum miR-145 and VEGF levels and $O S$. The patients had a median survival time of 14.24 months. The Kaplan-Meier curve showed that low miR-145 levels were associated with a significantly shorter OS $(\mathrm{P}=0.028)$, whereas low VEGF levels were associated with a longer OS $(\mathrm{P}=0.027)$ (Fig. 1C and D). Table IV shows the results of the multivariate Cox regression analysis. High miR-145 expression was independently associated with a higher OS [hazard ratio (HR), 0.48; 95\% CI, 0.27-0.85]. By contrast, high VEGF levels were associated with a lower OS (HR, 1.47; 95\% CI, 0.81-2.68); however, the association was not statistically significant. Stage and histological types were also significantly associated with OS, whereas age, smoking status, drinking status and family history of cancer were not.

Effects of upregulated miR-145 expression on cell viability. The functional role of miR-145 in A549 and H1792 adenocarcinoma cells was further explored following its overexpression. Transfection success was confirmed by measuring miR-145 expression levels using RT-qPCR. The results revealed that miR-145 expression levels were upregulated by 494- and 330-fold in transfected A549 and H1792 cells, respectively, compared with the cell group ( $\mathrm{P} \leq 0.001$; Fig. $2 \mathrm{~A}$ and $\mathrm{B})$. The expression of miR-145 was not significantly different among the control groups.

As determined using the trypan blue assay, miR-145 overexpression resulted in a $58.5 \%$ reduction in total A549 cell numbers and a $42.9 \%$ reduction in $\mathrm{H} 1792$ cell numbers 
A
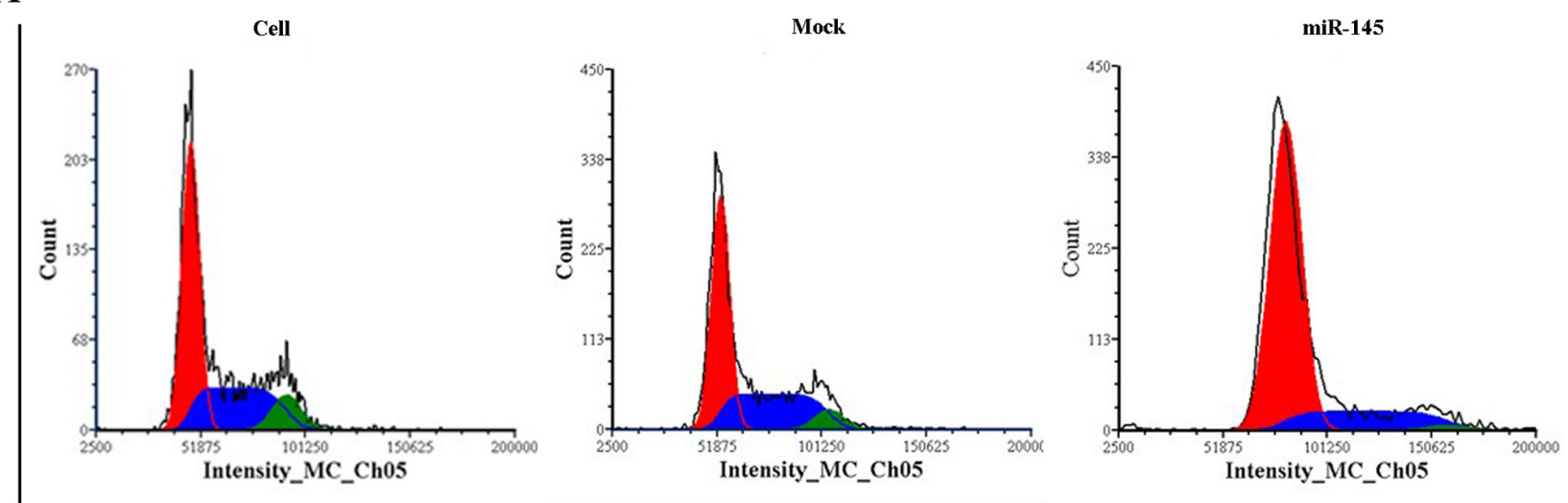

B

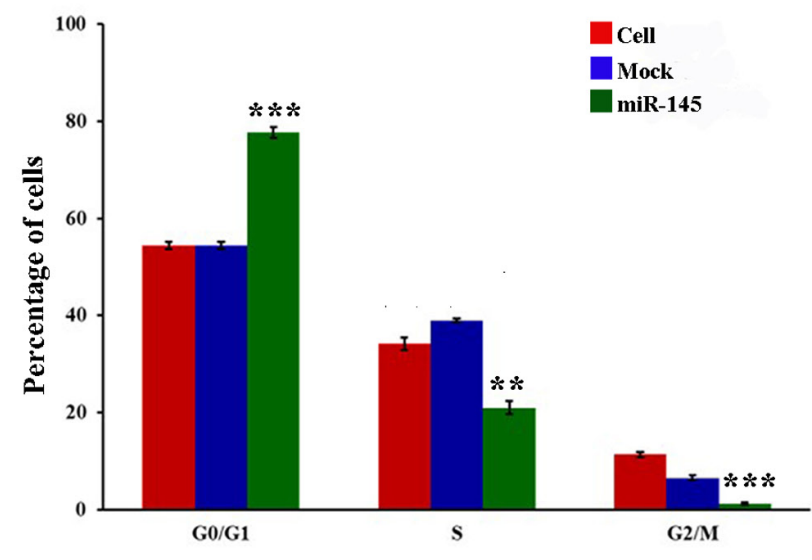

C

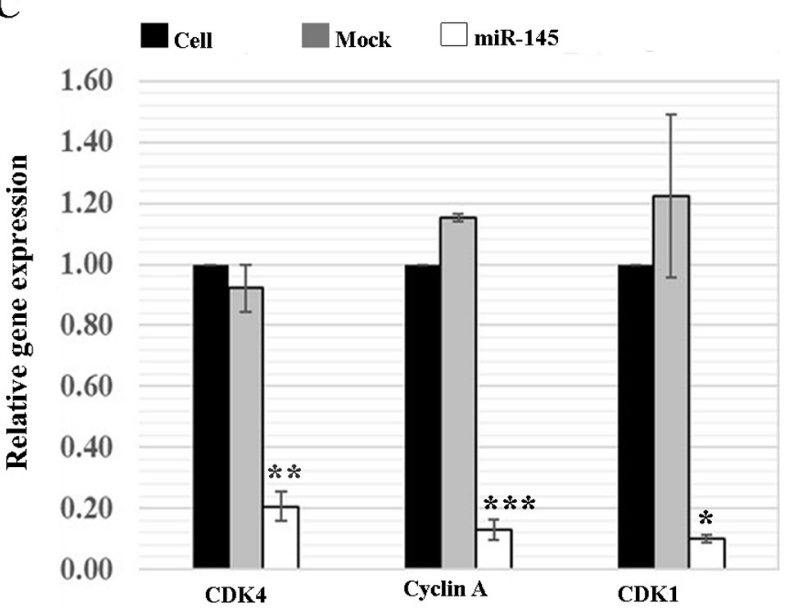

Figure 3. (A and B) Cell cycle progression was analyzed via flow cytometry in A549 cells. (C) Expression of cell cycle regulatory genes was determined using reverse transcription-quantitative PCR. All experiments were performed in triplicate on cell-culture passages $10-30$. Data are presented as the mean \pm SD from three independent experiments. ${ }^{* * * *} \mathrm{P} \leq 0.001,{ }^{* *} \mathrm{P} \leq 0.01,{ }^{*} \mathrm{P} \leq 0.05$ vs. cell group. miR, microRNA; NC, negative control.

compared with the cell group ( $\mathrm{P} \leq 0.001$; Fig. $2 \mathrm{C}$ and $\mathrm{D})$. Similarly, the results of the cell viability assay using the Muse cell analyzer revealed that the total cell numbers were significantly decreased following the overexpression of miR-145, by 45.0\% for A549 and 49.4\% for H1792 cells compared with those in the cell group ( $\mathrm{P} \leq 0.001$; Fig. $2 \mathrm{E}$ and $\mathrm{F})$. However, miR-145 overexpression had no effect on the number of viable and dead cells compared with in the control cells.

Effects of upregulated miR-145 expression on the cell cycle distribution. To further explore whether a reduction in total cell numbers following miR-145 overexpression was caused by cell cycle arrest, cell cycle analysis was performed using flow cytometry. Since there were no significant differences among the three control groups (data not shown), untreated cells and mock cells were used as the controls for subsequent experiments on the effects of miR-145 overexpression on cell cycle distribution and the expression of cell cycle regulatory genes. In A549 cells, the results revealed that the percentage of cells in $\mathrm{G}_{0} / \mathrm{G}_{1}$ phase was significantly increased by $42.7 \%(\mathrm{P} \leq 0.001)$ in the miR-145 mimic-transfected cells compared with the cell group. Significant reductions in the number of cells in the S-phase $(38.5 \% ; \mathrm{P} \leq 0.01)$ and $\mathrm{G} 2 / \mathrm{M}$-phase $(88.9 \% ; \mathrm{P} \leq 0.001)$ were also observed compared with the cell group (Fig. 3A and B). By contrast, the miR-145 mimic-transfected H1792 cells exhibited an $18.1 \%$ decrease in the percentage of cells in $G_{0} / G_{1}$ phase compared with that in the cell group $(P \leq 0.05)$, and a $36.4 \%$ increase in the percentage of cells in the $S$ phase compared with in the cell group ( $\mathrm{P} \leq 0.05$; Fig. 4A and B).

Effects of upregulated miR-145 expression on cell cycle regulatory genes. In A549 cells, the expression levels of CDK4, cyclin A and CDK1 were significantly downregulated in the miR-145 mimic-transfected cells by $81.0(\mathrm{P} \leq 0.01), 88.6$ $(\mathrm{P} \leq 0.001)$ and $91.5 \%(\mathrm{P} \leq 0.05)$, respectively, compared with those in the cell group (Fig. 3C). Similar to the A549 cells, there was a significant reduction in CDK4 (76.1\%; $\mathrm{P} \leq 0.001)$, cyclin A $(91.7 \%$; $\mathrm{P} \leq 0.01)$ and $\mathrm{CDK} 1(68.5 \%$; $\mathrm{P} \leq 0.05)$ expression in the miR-145 mimic-transfected H1792 cells when compared with the cell group (Fig. 4C).

\section{Discussion}

The results of the present study demonstrated that miR-145 and VEGF may be useful in terms of their clinical use as diagnostic and prognostic biomarkers in NSCLC. The data revealed that combining the evaluation of patient clinical factors, including age and smoking status, with the measurement of serum 
A

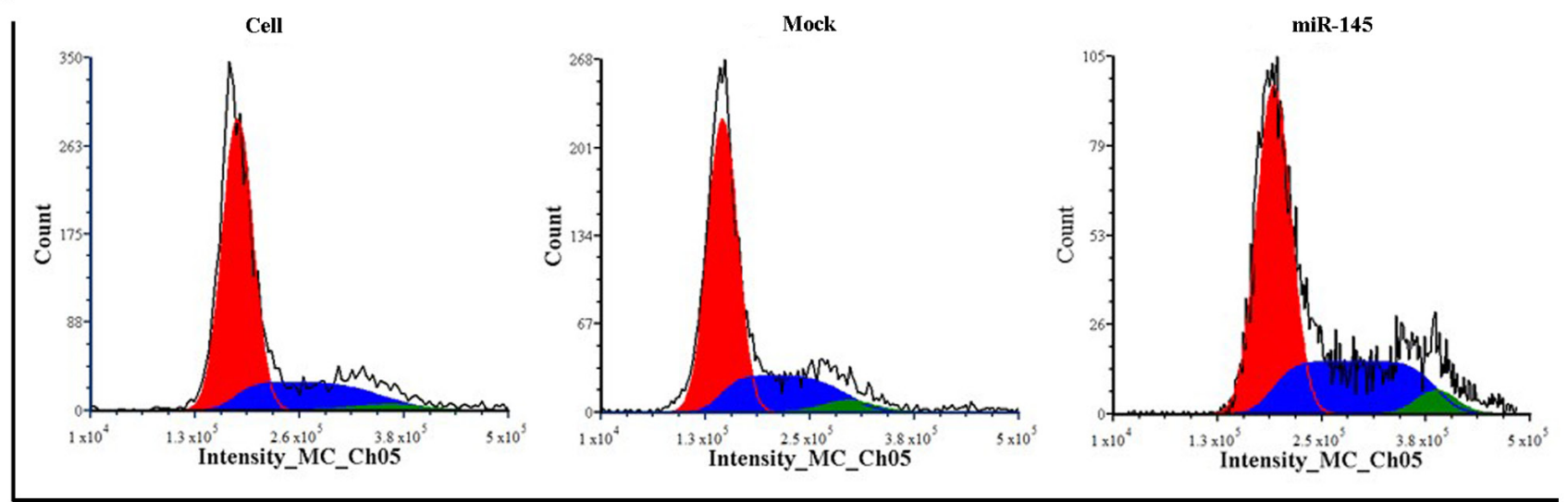

B

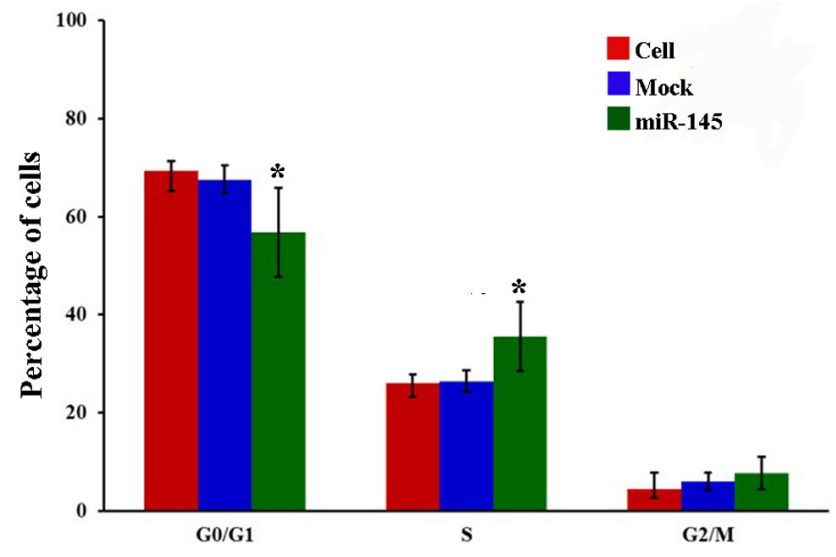

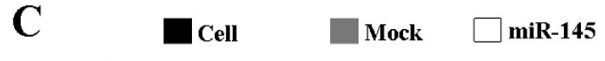

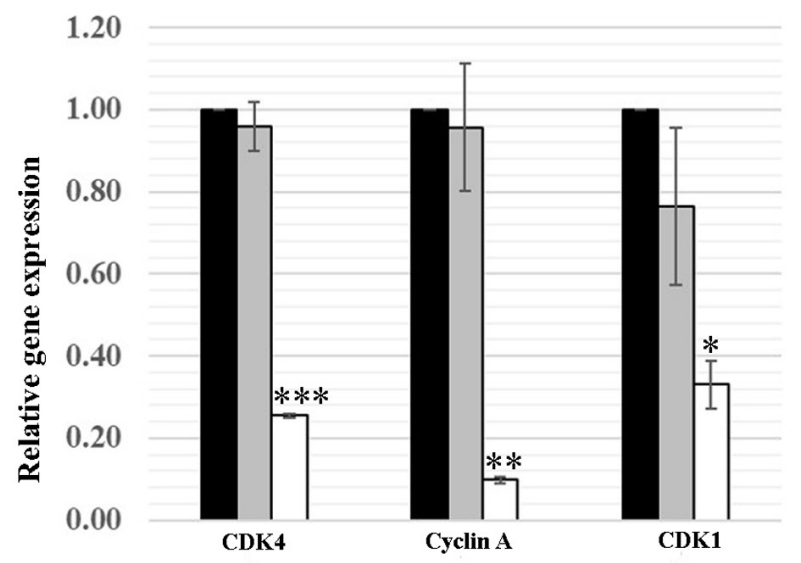

Figure 4. (A and B) Cell cycle progression was determined using flow cytometry in H1792 cells. (C) Expression of cell cycle regulatory genes was determined using reverse transcription-quantitative PCR. All experiments were performed in triplicate on cell-culture passages 10-30. Data are presented as the mean \pm SD from three independent experiments. ${ }^{* * * *} \mathrm{P} \leq 0.001,{ }^{* *} \mathrm{P} \leq 0.01,{ }^{*} \mathrm{P} \leq 0.05$ vs. cell group. miR, microR $\mathrm{NA}$; NC, negative control.

miR-145 and VEGF levels was the best model for differentiating patients with NSCLC from those with OLDs, yielding an AUC of 0.76 with $80.4 \%$ sensitivity and $65.9 \%$ specificity. The results also revealed that downregulated miR-145 and upregulated VEGF levels were significantly associated with poor survival, and that miR-145 expression was an independent prognostic biomarker for NSCLC. The in vitro experimental results also revealed that miR-145 overexpression reduced cell viability via the induction of cell cycle arrest.

Serum miR-145 expression was significantly decreased in patients with NSCLC compared with that in the control group. miR-145 expression has also been shown to be reduced in the serum of patients with glioblastoma (12) and ovarian cancer (13) when compared with healthy controls. However, the results of the present study differ from those of Wang et al (15), which reported higher serum miR-145 levels in patients with NSCLC $(n=70)$ compared with those in healthy controls $(n=70)$. The discrepancy may be due to the difference in histological ratio. The study by Wang et al (15) included 48 patients with adenocarcinoma and 20 with squamous cell carcinoma, whereas the present study included 77 patients with adenocarcinoma and 22 patients with squamous cell carcinoma. Similar to serum miR-145 levels, the trend in serum VEGF levels in the current study was similar to those of other studies. Numerous studies have reported higher serum VEGF levels in patients with cancer compared with in healthy individuals, including within breast (25), gastrointestinal (26), ovarian (14) and lung (27) cancer. Similarly, Zhang et al (27) revealed that VEGF levels were upregulated in patients with lung cancer compared with those with tuberculosis.

For diagnostic evaluations, the present study results demonstrated that the AUC of serum miR-145 was 0.61. By contrast, a study by Wang et al (15) indicated that serum miR-145 was a good biomarker for differentiating patients with NSCLC from healthy controls, with an AUC of 0.84 (15). The AUC for VEGF in the present study was 0.64 , which is similar to that measured in a study by Chakra et al (16), which reported an AUC value of 0.66 (16). The conflicting findings between the present results and those of the study by Wang et al (15) may be due to the use of a different control; the present study enrolled patients with OLDs as the control group, whereas the study by Wang et al included healthy individuals as the control group.

In the present study, clinical risk factors (age and smoking status) were measured alongside miR-145 and VEGF, and an increased AUC value was observed for the predictive model (AUC, 0.76), which is consistent with the findings of other studies $(20,28)$. For example, in a previous study, the combination of 24 miRNAs with major lung cancer risk factors, such 
as sex, age and smoking status, was discovered to improve the AUC to 0.94 compared with using the risk factors in isolation (AUC, 0.72) (28). Similar to the present study, our previous study showed that the AUC value of the combined clinical factors and miR-339-3p was increased to 0.71 compared with the AUC of miR-339-3p alone, which was 0.62 (20). This result suggested that a combination of biomarkers and risk factors may provide valuable insights for predictive accuracy.

In terms of the prognostic role, the findings of the present study revealed that low serum miR-145 and high VEGF levels were associated with poor survival in NSCLC. Zhang et al (12) revealed that patients with glioblastoma with low serum miR-145 levels had a shorter survival compared with those with high miR-145 levels. Similarly, Liang et al (13) demonstrated that low miR-145 expression was associated with the prognosis of ovarian cancer. These results indicated that miR-145 may be involved in lung tumorigenesis and may serve as an invasive prognostic biomarker for NSCLC. For VEGF, the findings of the present study identified no significant role as an independent prognostic biomarker for NSCLC. Previous studies have indicated that high serum VEGF levels may be an independent prognostic factor in ovarian (14) and gastrointestinal cancer (26). In lung cancer, two studies have indicated that high VEGF levels were useful for predicting a shorter OS $(16,29)$. By contrast, a study by Akın Kabalak et al (18) showed that serum VEGF levels did not significantly predict the prognosis of lung cancer, either in NSCLC or small cell lung cancer (18). Similarly, Zhang et al (27) found no differences in OS between patients with high and low serum VEGF levels in lung cancer. The results of the current study are consistent with those of the two latter studies, suggesting that high VEGF levels were not an independent prognostic biomarker. The small number of patients with NSCLC investigated in the present study may be one of the reasons for this lack of significance.

In the present study, the biological function of miR-145 in NSCLC was also examined. The results revealed that miR-145 led to a decrease in cell number, with no effect on cell death. Furthermore, miR-145 overexpression induced cell cycle arrest at the G0/G1-phase for A549 cells and at the S-phase for $\mathrm{H} 1792$ cells. This may indicate that miR-145 affected the cell cycle at different phases depending on the cell type. In addition, the present results revealed that miR-145 inhibited the cell cycle progression by modulating the expression of cell cycle regulators, including CDK1, CDK4 and cyclin A, in both A549 and H1792 cells. These results are consistent with previous studies from other groups, which reported that miR-145 prevented cell proliferation in gastric cancer (30), hepatocellular carcinoma (31) and NSCLC (32-34). In addition, previous studies have shown that increased miR-145 expression inhibited invasion and metastasis in numerous types of cancer, including osteosarcoma (35), hepatocellular carcinoma (31), nasopharyngeal carcinoma (36) and lung cancer (8). Taken together, the findings of the present study suggested that miR-145 may serve a crucial role in NSCLC as a tumor suppressor miRNA.

Nevertheless, there are several limitations to the current study that should be addressed in future research. Firstly, transcript levels only are not sufficient to predict protein levels; however, due to budget restrictions, only the alterations in gene expression levels were detected. Cell cycle analysis was performed and gene expression of related cell cycle regulators was determined, and the results suggested a potential role of miR-145 in cell cycle regulation. Regarding the clinical implications of miR-145 and VEGF, the ideal cancer diagnostic biomarker would be most beneficial if the cancer could be detected as early as possible. This type of study should include a substantial proportion of early-stage disease; however, in the present study, $>80 \%$ of the patients had late-stage disease, which may lead to an overestimated diagnostic power. However, OLDs were included as control subjects rather than healthy individuals, as this may have caused an overestimation of the diagnostic performance. Therefore, using the current study design, the resultant diagnostic power estimation, to a certain extent, was balanced.

In conclusion, the findings of the present study demonstrated that patients with NSCLC had lower serum miR-145 expression levels and higher serum VEGF levels compared with those in patients with OLDs. Serum miR-145 expression was identified to be a useful diagnostic and prognostic marker in NSCLC, whereas serum VEGF was only discovered to have potential as a diagnostic biomarker. The present study, which was based on findings obtained from clinical samples and in vitro experiments, suggested a role for miR-145 as a tumor suppressor in NSCLC. In addition, to the best of our knowledge, the present study led to the innovative finding that combined evaluation of miR-145 and VEGF enhanced the diagnostic performance of lung cancer diagnosis. However, further studies regarding the molecular target and specific biological pathway of miR-145 are warranted.

\section{Acknowledgements}

Not applicable.

\section{Funding}

The present study was funded by grants from the Faculty of Medicine, Prince of Songkla University (grant no. REC6131242) and the Prince of Songkla University, Songkhla, Thailand (grant no. MED61020002S).

\section{Availability of data and materials}

The datasets used and/or analyzed during the current study are available from the corresponding author on reasonable request.

\section{Authors' contributions}

PR, PT and SLG conceived and designed the study. PR, PC and KT developed and designed the methodology. SLG and WK acquired the clinical data and managed the patients. PR, SB and PT performed the statistical analysis and interpreted the data. PR and PT supervised the study. PR and PT confirmed the authenticity of all the raw data. All authors read and approved the final manuscript.

\section{Ethics approval and consent to participate}

The experiments were approved by the Human Research Ethics Committee of the Faculty of Medicine, Prince of Songkla 
University (approval nos. 59-011-05-1 and 60-350-04-2). Patients provided written informed consent.

\section{Patient consent for publication}

Not applicable.

\section{Competing interests}

The authors declare that they have no competing interests.

\section{References}

1. Sung H, Ferlay J, Siegel RL, Laversanne M, Soerjomataram I, Jemal A and Bray F: Global cancer statistics 2020: GLOBOCAN estimates of incidence and mortality worldwide for 36 cancers in 185 countries. CA Cancer J Clin 71: 209-249, 2021.

2. Cui M, Wang H, Yao X, Zhang D, Xie Y, Cui R and Zhang X: Circulating MicroRNAs in Cancer: Potential and Challenge. Front Genet 10: 626, 2019.

3. Hirales Casillas CE, Flores Fernández JM, Padilla Camberos E, Herrera López EJ, Leal Pacheco G and Martínez Velázquez M: Current status of circulating protein biomarkers to aid the early detection of lung cancer. Future Oncol 10: 1501-1513, 2014.

4. Bartel DP: MicroRNAs: Genomics, biogenesis, mechanism, and function. Cell 116: 281-297, 2004.

5. Xu W, Chang J, Du X and Hou J: Long non-coding RNA PCAT-1 contributes to tumorigenesis by regulating FSCN1 via miR-145-5p in prostate cancer. Biomed Pharmacother 95 $1112-1118,2017$

6. Zhang Y, Wen X, Hu XL, Cheng LZ, Yu JY and Wei ZB: Downregulation of miR-145-5p correlates with poor prognosis in gastric cancer. Eur Rev Med Pharmacol Sci 20: 3026-3030, 2016.

7. Chang Y, Yan W, Sun C, Liu Q, Wang J and Wang M: miR-145-5p inhibits epithelial-mesenchymal transition via the JNK signaling pathway by targeting MAP3K1 in non-small cell lung cancer cells. Oncol Lett 14: 6923-6928, 2017.

8. Wang M, Wang J, Deng J, Li X, Long W and Chang Y: MiR-145 acts as a metastasis suppressor by targeting metadherin in lung cancer. Med Oncol 32: 344, 2015.

9. Kieran MW, Kalluri R and Cho YJ: The VEGF pathway in cancer and disease: Responses, resistance, and the path forward. Cold Spring Harb Perspect Med 2: a006593, 2012.

10. Zou C, Xu Q, Mao F, Li D, Bian C, Liu LZ, Jiang Y, Chen X, Qi Y, Zhang X, et al: MiR-145 inhibits tumor angiogenesis and growth by N-RAS and VEGF. Cell Cycle 11: 2137-2145, 2012.

11. Chaniad P, Trakunran K, Geater SL, Keeratichananont W, Thongsuksai P and Raungrut P: Serum miRNAs associated with tumor-promoting cytokines in non-small cell lung cancer. PLoS One 15: e0241593, 2020.

12. Zhang Y, Ta WW, Sun PF, Meng YF and Zhao CZ: Diagnostic and prognostic significance of serum miR-145-5p expression in glioblastoma. Int J Clin Exp Pathol 12: 2536-2543, 2019.

13. Liang H, Jiang Z, Xie G and Lu Y: Serum microRNA-145 as a novel biomarker in human ovarian cancer. Tumour Biol 36 5305-5313, 2015

14. Komatsu H, Oishi T, Itamochi H, Shimada M, Sato S, Chikumi J, Sato S, Nonaka M, Sawada M, Wakahara M, et al: Serum vascular endothelial growth factor-A as a prognostic biomarker for epithelial ovarian cancer. Int J Gynecol Cancer 27: 1325-1332, 2017.

15. Wang RJ, Zheng YH, Wang P and Zhang JZ: Serum miR-125a-5p, miR-145 and miR-146a as diagnostic biomarkers in non-smal cell lung cancer. Int J Clin Exp Pathol 8: 765-771, 2015.

16. Chakra M, Pujol JL, Lamy PJ, Bozonnat MC, Quantin X, Jacot W and Daurès JP: Circulating serum vascular endothelial growth factor is not a prognostic factor of non-small cell lung cancer. J Thorac Oncol 3: 1119-1126, 2008.

17. Shen H, Shen J, Wang L, Shi Z, Wang M, Jiang BH and Shu Y: Low miR-145 expression level is associated with poor pathological differentiation and poor prognosis in non-small cell lung cancer. Biomed Pharmacother 69: 301-305, 2015

18. Akın Kabalak P, C.iledağ A, Demir N, Çelik G, Yüksel C Köycü G, Gökmen Öztuna D, Taner A, Kaya A, Kutlay H, et al: Prognostic significance of serum vascular endothelial growth factor and Angiopoietin-2 in patients with lung cancer. Tuberk Toraks 63: 71-77, 2015.
19. Bossuyt PM: Clinical validity: Defining biomarker performance. Scand J Clin Lab Invest Suppl 242: 46-52, 2010.

20. Trakunram K, Chaniad P, Geater SL, Keeratichananont W, Chittithavorn V, Uttayamakul S, Buya S, Raungrut P and Thongsuksai P: Serum miR-339-3p as a potential diagnostic marker for non-small cell lung cancer. Cancer Biol Med 17: 652-663, 2020.

21. Travis WD, Brambilla E, Nicholson AG, Yatabe Y, Austin JHM, Beasley MB, Chirieac LR, Dacic S, Duhig E, Flieder DB, et al WHO Panel: The 2015 World Health Organization Classification of Lung Tumors: Impact of genetic, clinical and radiologic advances since the 2004 classification. J Thorac Oncol 10: 1243-1260, 2015

22. Edge SB and Compton CC: The American Joint Committee on Cancer: the 7th edition of the AJCC cancer staging manual and the future of TNM. Ann Surg Oncol 17: 1471-1474, 2010.

23. Rao X, Huang X, Zhou Z and Lin X: An improvement of the $2^{\wedge}$ (-delta delta CT) method for quantitative real-time polymerase chain reaction data analysis. Biostat Bioinforma Biomath 3: 71-85, 2013.

24. Livak KJ and Schmittgen TD: Analysis of relative gene expression data using real-time quantitative PCR and the 2(-Delta Delta C(T)) Method. Methods 25: 402-408, 2001

25. Li S, Wang L, Meng Y, Chang Y, Xu J and Zhang Q: Increased levels of LAPTM4B, VEGF and survivin are correlated with tumor progression and poor prognosis in breast cancer patients. Oncotarget 8: 41282-41293, 2017.

26. Jiang L, Hochwald S, Deng S, Chen Y, Tan C, Zhong Q and Huang H: Diagnostic and prognostic performance of serum vascular endothelial growth factor, vascular endothelial growth factor receptor 2, and osteopontin for gastrointestinal cancers. Clin Lab 65: 65, 2019.

27. Zhang Y, Yu LK, Lu GJ, Xia N, Xie HY, Hu W, Hao KK, Xu CH and Qian Q: Prognostic values of VEGF and endostatin with malignant pleural effusions in patients with lung cancer. Asian Pac J Cancer Prev 15: 8435-8440, 2014.

28. Wozniak MB, Scelo G, Muller DC, Mukeria A, Zaridze D and Brennan P: Circulating microRNAs as non-invasive biomarkers for early detection of non-small-cell lung cancer. PLoS One 10: e0125026, 2015.

29. Shimanuki Y, Takahashi K, Cui R, Hori S, Takahashi F, Miyamoto $\mathrm{H}$ and Fukurchi Y: Role of serum vascular endothelial growth factor in the prediction of angiogenesis and prognosis for non-small cell lung cancer. Lung 183: 29-42, 2005.

30. Zeinali T, Karimi L, Hosseinahli N, Shanehbandi D, Mansoori B, Mohammadi A, Hajiasgharzadeh K, Babaloo Z, Majidi-Zolbanin J and Baradaran B: Overexpression of miRNA-145 induces apoptosis and prevents proliferation and migration of MKN-45 gastric cancer cells. EXCLI J 19: 1446-1458, 2020.

31. Ding W, Tan H, Zhao C, Li X, Li Z, Jiang C, Zhang Y and Wang L: MiR-145 suppresses cell proliferation and motility by inhibiting ROCK1 in hepatocellular carcinoma. Tumour Biol 37: 6255-6260, 2016

32. Pan Y, Ye C, Tian Q, Yan S, Zeng X, Xiao C, Wang L and Wang H: miR-145 suppresses the proliferation, invasion and migration of NSCLC cells by regulating the BAX/BCL-2 ratio and the caspase-3 cascade. Oncol Lett 15: 4337-4343, 2018.

33. Ye Z, Shen N, Weng Y, Li K, Hu L, Liao H, An J, Liu L, Lao S and Cai S: Low miR-145 silenced by DNA methylation promotes NSCLC cell proliferation, migration and invasion by targeting mucin 1. Cancer Biol Ther 16: 1071-1079, 2015.

34. Chen Z, Zeng H, Guo Y, Liu P, Pan H, Deng A and Hu J: miRNA-145 inhibits non-small cell lung cancer cell proliferation by targeting c-Myc. J Exp Clin Cancer Res 29: 151, 2010.

35. Fan L, Wu Q, Xing X, Wei Y and Shao Z: MicroRNA-145 targets vascular endothelial growth factor and inhibits invasion and metastasis of osteosarcoma cells. Acta Biochim Biophys Sin (Shanghai) 44: 407-414, 2012.

36. Li YQ, He QM, Ren XY, Tang XR, Xu YF, Wen X, Yang XJ, Ma J and Liu N: MiR-145 inhibits metastasis by targeting fascin actin-bundling protein 1 in nasopharyngeal carcinoma. PLoS One 10: e0122228, 2015.

This work is licensed under a Creative Commons Attribution-NonCommercial-NoDerivatives 4.0 International (CC BY-NC-ND 4.0) License. 